\title{
Mortality among survivors of the Sept 11, 2001, World Trade Center disaster: results from the World Trade Center Health Registry cohort
}

\author{
Hannah T Jordan, Robert M Brackbill, James E Cone, Indira Debchoudhury, Mark R Farfel, Carolyn M Greene, James L Hadler, Joseph Kennedy, \\ Jiehui Li, Jonathan Liff, Leslie Stayner, Steven D Stellman
}

\section{Summary}

Background The Sept 11, 2001 (9/11) World Trade Center (WTC) disaster has been associated with several subacute and chronic health effects, but whether excess mortality after 9/11 has occurred is unknown. We tested whether excess mortality has occurred in people exposed to the WTC disaster.

Methods In this observational cohort study, deaths occurring in 2003-09 in WTC Health Registry participants residing in New York City were identified through linkage to New York City vital records and the National Death Index. Eligible participants were rescue and recovery workers and volunteers; lower Manhattan area residents, workers, school staff and students; and commuters and passers-by on $9 / 11$. Study participants were categorised as rescue and recovery workers (including volunteers), or non-rescue and non-recovery participants. Standardised mortality ratios (SMR) were calculated with New York City rates from 2000-09 as the reference. Within the cohort, proportional hazards were used to examine the relation between a three-tiered WTC-related exposure level (high, intermediate, or low) and total mortality.

Findings We identified 156 deaths in 13337 rescue and recovery workers and 634 deaths in 28593 non-rescue and nonrecovery participants. All-cause SMRs were significantly lower than that expected for rescue and recovery participants (SMR 0.45, 95\% CI 0.38-0.53) and non-rescue and non-recovery participants $(0.61,0.56-0.66)$. No significantly increased SMRs for diseases of the respiratory system or heart, or for haematological malignancies were found. In nonrescue and non-recovery participants, both intermediate and high levels of WTC-related exposure were significantly associated with mortality when compared with low exposure (adjusted hazard ratio 1.22, 95\% CI 1.01-1.48, for intermediate exposure and $1 \cdot 56,1 \cdot 15-2 \cdot 12$, for high exposure). High levels of exposure in non-rescue and non-recovery individuals, when compared with low exposed non-rescue and non-recovery individuals, were associated with heartdisease-related mortality (adjusted hazard ratio $2 \cdot 06,1 \cdot 10-3 \cdot 86$ ). In rescue and recovery participants, level of WTCrelated exposure was not significantly associated with all-cause mortality (adjusted hazard ratio 1.25, 95\% CI $0 \cdot 56-2 \cdot 78$, for high exposure and 1.03, 0.52-2.06, for intermediate exposure when compared with low exposure).

Interpretation This exploratory study of mortality in a well defined cohort of $9 / 11$ survivors provides a baseline for continued surveillance. Additional follow-up is needed to establish whether these associations persist and whether a similar association over time will occur in rescue and recovery participants.

Funding US Centers for Disease Control and Prevention (National Institute for Occupational Safety and Health, Agency for Toxic Substances and Disease Registry, and National Center for Environmental Health); New York City Department of Health and Mental Hygiene.

\section{Introduction}

In the years since Sept 11, 2001 (9/11), exposure to the World Trade Center (WTC) disaster and its aftermath has been associated with several chronic physical and psychological health effects. An increased risk of asthma and other respiratory illnesses has been reported in people exposed to smoke, fumes, and dust released during the disaster and subsequent rescue, recovery, and clean-up activities. ${ }^{1-4}$ Psychological trauma resulting from the disaster was associated with a heightened risk of post-traumatic stress disorder (PTSD) and serious psychological distress. ${ }^{15,6}$ Directly exposed individuals might also be at risk for premature death due to new-onset respiratory diseases, exacerbation of pre-existing respiratory disorders, or complications of mental health disorders, including substance abuse.

Although respiratory illnesses and PTSD are the main sequelae of $9 / 11$ described so far, ${ }^{1-6}$ the detection of several carcinogens in WTC dust has raised concern that exposure could have increased the risk of cancer. ${ }^{7-9}$ Insufficient time has passed to establish whether exposure conferred an increased risk for most cancers. However, an increase in the incidence of haematological malignancies, which have fairly short latency periods, could be detected within several years after 9/11; a case series of multiple myeloma in WTC rescue and recovery workers has been reported. ${ }^{10}$ Cardiovascular disease has been associated with exposure to both psychological stress $^{11}$ and inhaled particulate matter, ${ }^{12}$ therefore a
Lancet 2011; 378: 879-87 See Comment page 851 New York City Department of Health and Mental Hygiene, Long Island City, NY, USA (HT Jordan MD, $\mathrm{R}$ M Brackbill PhD, J E Cone MD, I Debchoudhury MPH M R Farfel ScD, C M Greene MD, J L Hadler MD, J Kennedy MPH, J Li MS, S D Stellman PhD); Department of Epidemiology, Rollins School of Public Health, Emory University, Atlanta, GA USA (J Liff PhD); Division of Epidemiology and Biostatistics, School of Public Health, University of Illinois, Chicago, IL, USA (LStayner PhD); and Department of Epidemiology, Mailman School of Public Health, Columbia University, New York, NY, USA (SD Stellman)

Correspondence to: Dr James E Cone, World Trade Center Health Registry, New York City Department of Health and Mental Hygiene, 42-09 28th Street, 7th floor, Long Island City, NY 11101, USA jcone@health.nyc.gov 
reasonable biological mechanism could also be postulated for a relation between WTC exposure and cardiovascular disease. Ecological studies have suggested such an association, ${ }^{13,14}$ but definitive studies are not yet available.

We sought to determine whether excess mortality has occurred in people exposed to the $9 / 11$ disaster. We also examined relations between WTC-related exposures and specific causes of death that could be related to those exposures, including respiratory diseases, complications of mental illness, haematological malignancies, and cardiovascular disease.

\section{Methods \\ Study population}

The methods used to gather data for the WTC Health Registry are described elsewhere. ${ }^{1,15}$ Between Sept 12, 2003, and Nov 24, 2004, 71437 people completed a computerassisted $(95 \%)$ or in-person $(5 \%)$ enrolment interview on demographics, exposures incurred during and after the WTC disaster, and health information. All participants provided verbal informed consent for their responses to be used in data linkages and analyses. Eligible participants were rescue and recovery workers and volunteers (ie, those involved in rescue, recovery, cleanup work at the WTC site, Fresh Kills Landfill [Staten Island], or transporting debris via barges), lower Manhattan area residents, workers, school staff and attendees, and commuters and passers-by on $9 / 11$. Lists of eligible participants were obtained from lower Manhattan area employers and government agencies (list-identified participants), and broad-based, multilingual

Panel 1: Three-tiered definitions of the overall levels of exposure to the World Trade Center incurred for rescue and recovery and non-rescue and non-recovery participants

\section{Definitions of WTC-related rescue and recovery exposure*}

- High exposure: participants who were in Manhattan, south of Chambers Street, between the time of the first plane impact and $1200 \mathrm{~h}$ on $9 / 11$ (encompassing the collapse of WTC towers) and who worked on the WTC dust and debris pile on $9 / 11$ or worked at the WTC site for more than 90 days, starting before Sept 18, 2001.

- Low exposure: participants who began work at the WTC site after Sept 17, 2001, did not work on the WTC debris pile, worked fewer than 30 days at the WTC site, and were not present south of Chambers Street between the first plane impact and $1200 \mathrm{~h}$ on 9/11.

- Intermediate: participants whose level of exposure fell between high and low.

\section{Definitions of WTC-related residential, office, school, or transit exposure}

- High exposure: participants who reported two or more injuries on 9/11, and for residents in zip codes including Canal Street and south, in lower Manhattan, who did not evacuate their home on $9 / 11$, and for school students and school staff south of Canal Street, who were present at school on 9/11.

- Low exposure: participants who reported no injuries on 9/11, residents in zip codes including Canal Street and south, in lower Manhattan, who also evacuated their home on 9/11 (for any amount of time), and school students and school staff south of Canal Street, who were not present at school on 9/11.

- Intermediate exposure: participants whose exposure level fell between high and low.

*Rescue and recovery workers who worked exclusively on Staten Island, barges, or transfer stations were excluded. 9/11=Sept 11, 2001. WTC=World Trade Center. media campaigns encouraged WTC-exposed people to contact the Registry via a website or toll-free telephone number for eligibility screening, which consisted of several questions related to exposure to the WTC disaster. We refer to those recruited through the media campaigns as selfidentified participants. The US Centers for Disease Control and Prevention (CDC) and New York City Department of Health and Mental Hygiene institutional review boards approved the Registry protocol.

\section{Procedures}

We used New York City vital records as the primary source of mortality data because it provided the most upto-date information, and because $60 \%$ of Registry participants resided in New York City on Registry enrolment. This analysis was therefore limited to participants residing in the city at enrolment. We excluded those for whom both age and date of birth were missing (158) and rescue and recovery workers who worked only on the Staten Island recovery operation landfill or barge because of scarcity of information about their specific tasks and exposures (378).

Data that identified study participants were linked to death certificates in New York City vital records from Jan 1 , 2003, to Dec 31, 2009. Potential matches were records that matched parts of key identifiers such as name, address date of birth, and social security number. Key identifiers from the Registry and datasets from the vital records were electronically compared and a score was assigned for each potential match on the basis of degree of similarity. These scores aided identification of deaths of Registry enrolled participants during manual review by two independent reviewers. In the case of disagreement, a third reviewer determined whether the case was a match. Deaths among New York City residents occurring outside the city, which were not recorded in vital records, were identified by linkage to the National Death Index up to Dec 31, 2007the most recent year in which these data were available at the time of analysis. Participants who were not linked to a death certificate were judged to be alive as of Dec 31, 2009. We did not have National Death Index mortality data for 2008-09, and therefore could not identify deaths occurring during those years among participants who had moved out of New York City after study enrolment (about 24 additional deaths).

Study participants were categorised as rescue and recovery workers (including volunteers), or non-rescue and non-recovery participants (including lower Manhattan area residents, workers, school staff or students, and commuters and passers-by on 9/11). Participants who did rescue and recovery work but also belonged to one of the other groups were classed as rescue and recovery workers.

International Classification of Disease codes, 10th revision (ICD-10), for underlying cause of death ${ }^{16}$ were obtained from New York City vital records or the National Death Index and categorised according to the 119-cause 
rate file from the National Institute for Occupational Safety and Health's (NIOSH) life table analysis software (LTAS.NET). ${ }^{17}$

WTC exposures were defined on the basis of responses to the 2003-04 enrolment questionnaires. All participants were asked whether they were caught in the dust or debris cloud on $9 / 11$, and whether they had any of the following acute injuries on the day due to the disaster: cut, abrasion, or puncture wound; eye injury or irritation; sprain or strain; burn; broken or dislocated bone; or concussion or head injury. Participants classed as rescue and recovery workers were asked about the date of arrival for work, number of days worked, whether work was done on the WTC dust and debris pile, and type of tasks they undertook. To enable comparisons within the cohort, we explored ways to classify the overall level of WTCrelated exposure into distinct high and low categories. We developed summary definitions on the basis of consistently reported associations between the individual component variables and adverse WTC-related health outcomes. ${ }^{1,15,18}$ Dust cloud exposure was analysed separately. We created separate three-tiered definitions of the overall levels of exposure incurred for each of the two categories of study participants (rescue and recovery and non-rescue and non-recovery participants; panel 1). The combinations of variables that best predicted the risk of asthma after $9 / 11$ were retained, because asthma is the most commonly reported respiratory disorder in WTCexposed people, and a dose-response relation between WTC-related exposures and asthma has consistently been identified in both rescue and recovery participants and non-rescue and non-recovery participants in several WTC-survivor study cohorts. ${ }^{1,4,19,20}$

We defined pre-9/11 heart disease as self-reported, physician-diagnosed coronary artery disease, angina, heart attack, or any other heart disorder before $9 / 11$, and pre-9/11 cancer as self-reported, physician-diagnosed cancer, except for non-melanoma skin cancer, before $9 / 11$. Participants reporting physician-diagnosed heart disease, stroke, emphysema, diabetes, or cancer before $9 / 11$ were judged to have pre-9/11 chronic disease. For participants missing income data (6918 [16.5\%]), income was assigned from the median income for their home zip code obtained from 2000 US census data.

\section{Statistical analysis}

Person-time began on the date of participant enrolment into the WTC Health Registry and ended on the date of death or Dec 31, 2009, whichever came earlier. We analysed data for rescue and recovery participants and non-rescue and non-recovery participants separately because of striking differences between sociodemographic and WTC-exposure characteristics. Standardised mortality ratios (SMRs) adjusted for age, sex, race, and calendar year were calculated with LTAS.NET ${ }^{17}$ to compare the observed number of deaths with the expected number on the basis of the New York City reference population;
95\% CIs were calculated on the basis of Poisson distribution. SMR calculations included person-time and deaths of individuals aged 15 years or older during the study. For people who attained age 15 years during the study, the 15th birthday was judged to be the risk begin date, and person-time and any deaths subsequent to that date were included in SMR calculations.

\begin{tabular}{|c|c|c|}
\hline & $\begin{array}{l}\text { Rescue and recovery } \\
\text { participants }(\mathrm{N}=13337)\end{array}$ & $\begin{array}{l}\text { Non-rescue and } \\
\text { non-recovery participants* } \\
\text { ( } \mathrm{N}=28593)\end{array}$ \\
\hline Person-years of observation & 74967 & 161519 \\
\hline \multicolumn{3}{|l|}{ Age on 9/11 (years) } \\
\hline$<25$ & $820(6 \%)$ & $4759(17 \%)$ \\
\hline $25-44$ & $8277(62 \%)$ & $12119(42 \%)$ \\
\hline $45-64$ & $4101(31 \%)$ & $9957(35 \%)$ \\
\hline$\geq 65$ & $139(1 \%)$ & $1758(6 \%)$ \\
\hline \multicolumn{3}{|l|}{ Sex } \\
\hline Male & $10149(76 \%)$ & $11860(41 \%)$ \\
\hline Female & $3188(24 \%)$ & $16733(59 \%)$ \\
\hline \multicolumn{3}{|l|}{ Race and ethnic origin } \\
\hline Non-Hispanic white & $7580(57 \%)$ & $14380(50 \%)$ \\
\hline Non-Hispanic black & $1957(15 \%)$ & $4764(17 \%)$ \\
\hline Hispanic & $2781(21 \%)$ & $4335(15 \%)$ \\
\hline Other & $1019(8 \%)$ & $5114(18 \%)$ \\
\hline \multicolumn{3}{|l|}{ Study recruitment source } \\
\hline Self-identified & $8781(66 \%)$ & $21837(76 \%)$ \\
\hline List-identified & $4556(34 \%)$ & $6756(24 \%)$ \\
\hline \multicolumn{3}{|c|}{ Total household income (\$US) in 2002} \\
\hline$<25000$ & $1342(10 \%)$ & $4973(18 \%)$ \\
\hline 25000-49999 & $3559(27 \%)$ & $8932(32 \%)$ \\
\hline $50000-74999$ & $3550(27 \%)$ & $4855(17 \%)$ \\
\hline$\geq 75000$ & $4847(36 \%)$ & $9025(33 \%)$ \\
\hline \multicolumn{3}{|c|}{ Smoking status at study enrolment } \\
\hline Never & $7078(54 \%)$ & $17321(61 \%)$ \\
\hline Former & $3433(26 \%)$ & $6698(23 \%)$ \\
\hline Current & $2681(20 \%)$ & $4210(15 \%)$ \\
\hline \multicolumn{3}{|c|}{ History of chronic illness before $9 / 11$} \\
\hline Yes & $1128(9 \%)$ & $3382(12 \%)$ \\
\hline No & $11927(91 \%)$ & $24620(86 \%)$ \\
\hline \multicolumn{3}{|c|}{ WTC-related rescue and recovery exposure level $\dagger$} \\
\hline Low & $913(7 \%)$ & .. \\
\hline Intermediate & $10599(81 \%)$ & .. \\
\hline High & $1639(12 \%)$ & .. \\
\hline \multicolumn{3}{|c|}{ WTC-related residential, office, school or transit exposure level ${ }^{\dagger}$} \\
\hline None & $10130(76 \%)$ & .. \\
\hline Low & $1131(8 \%)$ & $13132(46 \%)$ \\
\hline Intermediate & $1496(11 \%)$ & $12965(45 \%)$ \\
\hline High & $545(4 \%)$ & $2091(7 \%)$ \\
\hline \multicolumn{3}{|c|}{$\begin{array}{l}\text { Dataare number (\%). The study cohort was composed of World Trade Center Health Registry participants who resided } \\
\text { in New York City at the time of registry enrolment. Frequencies might not sum to total because of missing values. } \\
\text { Percentages might not sum to } 100 \% \text { due to rounding or missing values. } 9 / 11=S \text { ept } 11,2001 \text {. WTC=World Trade Center. } \\
\text { *Non-rescue and non-recovery worker category includes residents, workers, and school students and school staff, and } \\
\text { passers-by of the lower Manhattan area, on 9/11. tPlease see panel } 1 \text { for definitions of exposure levels. }\end{array}$} \\
\hline
\end{tabular}




\begin{tabular}{|c|c|c|c|c|c|c|}
\hline & \multicolumn{2}{|c|}{ All participants } & \multicolumn{2}{|c|}{$\begin{array}{l}\text { Rescue and recovery } \\
\text { participants }\end{array}$} & \multicolumn{2}{|c|}{$\begin{array}{l}\text { Non-rescue and non-recovery } \\
\text { participants* }\end{array}$} \\
\hline & $n$ & $\operatorname{SMR}(95 \% \mathrm{Cl})$ & $\mathrm{n}$ & $\operatorname{SMR}(95 \% \mathrm{Cl})$ & $\mathrm{n}$ & $\operatorname{SMR}(95 \% \mathrm{Cl})$ \\
\hline All & 790 & $0.57(0.53-0.61) \dagger$ & 156 & $0.45(0.38-0.53) \dagger$ & 634 & $0.61(0.56-0.66) \dagger$ \\
\hline Tuberculosis and HIV-related disease (01) & 20 & $0.30(0.18-0.46) \dagger$ & 4 & $0.14(0.04-0.36) \dagger$ & 16 & $0.41(0.23-0.66) \dagger$ \\
\hline MN of buccal cavity and pharynx (02) & 6 & $0.87(0.32-1.90)$ & 3 & $1 \cdot 30(0.27-3 \cdot 80)$ & 3 & $0.66(0.14-1.92)$ \\
\hline MN of digestive organs and peritoneum (03) & 75 & $0.71(0.55-0.88) \dagger$ & 20 & $0.72(0.44-1 \cdot 11)$ & 55 & $0.70(0.53-0.91) \dagger$ \\
\hline MN of respiratory system (04) & 70 & $0.81(0.63-1.02)$ & 12 & $0.54(0.28-0.94) \ddagger$ & 58 & $0.90(0.69-1.17)$ \\
\hline MN of breast (05) & 26 & $0.77(0.51-1 \cdot 13)$ & 1 & $0.22(0.01-1 \cdot 21)$ & 25 & $0.86(0.56-1 \cdot 27)$ \\
\hline MN of female genital organs (06) & 19 & $0.82(0.49-1.28)$ & 2 & $0.67(0.08-2.43)$ & 17 & $0 \cdot 84(0 \cdot 49-1 \cdot 35)$ \\
\hline MN of male genital organs $(07)$ & 10 & $0.58(0.28-1.07)$ & 1 & $0.28(0.01-1 \cdot 54)$ & 9 & $0.66(0.30-1.25)$ \\
\hline MN of urinary organs $(08)$ & 15 & $1.18(0.66-1.95)$ & 2 & $0.63(0.08-2.27)$ & 13 & $1 \cdot 37(0.73-2 \cdot 34)$ \\
\hline MN of other and unspecified sites (09) & 36 & $0.93(0.65-1.29)$ & 11 & $1.04(0.52-1.87)$ & 25 & $0.89(0.57-1.31)$ \\
\hline Neoplasms of lymphatic and haematopoietic tissue (10) & 27 & $0.81(0.53-1.18)$ & 5 & $0.56(0.18-1 \cdot 30)$ & 22 & $0.90(0.57-1 \cdot 37)$ \\
\hline Benign and unspecified neoplasms (11) & 8 & $1 \cdot 79(0 \cdot 77-3 \cdot 53)$ & 3 & $2.77(0.57-8.10)$ & 5 & $1.48(0.48-3.45)$ \\
\hline Diseases of the blood and blood forming organs (12) & 1 & $0.20(0.00-1.09)$ & 0 & $0.00(0.00-2.78)$ & 1 & $0.26(0.01-1.47)$ \\
\hline Diabetes mellitus (13) & 24 & $0.50(0.32-0.75) \dagger$ & 1 & $0.09(0.00-0.50) \dagger$ & 23 & $0.63(0.40-0.95) \ddagger$ \\
\hline Mental psychoneurotic and personality disorders (14) & 22 & $0.85(0.53-1.29)$ & 9 & $0.97(0.44-1.85)$ & 13 & $0.79(0.42-1 \cdot 35)$ \\
\hline Diseases of the nervous system and sense organs (15) & 14 & $0.93(0.51-1 \cdot 55)$ & 1 & $0 \cdot 31(0.01-1 \cdot 75)$ & 13 & $1.09(0.58-1.86)$ \\
\hline Diseases of the heart (16) & 187 & $0.42(0.36-0.48) \dagger$ & 34 & $0.39(0.27-0.54) \dagger$ & 153 & $0.42(0.36-0.50) \dagger$ \\
\hline Other diseases of the circulatory system (17) & 44 & $0.54(0.39-0.72) \dagger$ & 6 & $0.33(0.12-0.72) \dagger$ & 38 & $0.60(0.42-0.82) \dagger$ \\
\hline Diseases of the respiratory system (18) & 57 & $0.64(0.48-0.83) \dagger$ & 3 & $0.18(0.04-0.54) \dagger$ & 54 & $0.74(0.55-0.96) \ddagger$ \\
\hline Diseases of the digestive system (19) & 26 & $0.60(0.39-0.87) \dagger$ & 7 & $0.52(0.21-1.06)$ & 19 & $0.63(0.38-0.99) \ddagger$ \\
\hline Diseases of the skin and subcutaneous tissue (20) & 3 & $1.50(0.31-4 \cdot 40)$ & 0 & $0.00(0.00-9.54)$ & 3 & $1.87(0.38-5 \cdot 45)$ \\
\hline Disease of the musculoskeletal and connective systems (21) & 5 & $0.86(0.28-2 \cdot 00)$ & 0 & $0.00(0 \cdot 00-2 \cdot 71)$ & 5 & $1.12(0.36-2 \cdot 61)$ \\
\hline Diseases of the genitourinary system (22) & 8 & $0.36(0.15-0.70) \dagger$ & 0 & $0.00(0.00-0.93) \ddagger$ & 8 & $0.43(0.19-0.85) \ddagger$ \\
\hline Symptoms and ill-defined conditions (23) & 2 & $0.19(0.02-0.68) \dagger$ & 0 & $0.00(0.00-0.92) \ddagger$ & 2 & $0.30(0.04-1.09)$ \\
\hline Transportation injuries (24) & 6 & $0.41(0.15-0.90) \ddagger$ & 3 & $0.56(0.11-1 \cdot 63)$ & 3 & $0.33(0.07-0.96) \ddagger$ \\
\hline Falls (25) & 8 & $0.82(0.36-1.62)$ & 1 & $0.36(0.01-2 \cdot 01)$ & 7 & $1.01(0.40-2 \cdot 07)$ \\
\hline Other injury (26) & 22 & $0.46(0.29-0.70) \dagger$ & 12 & $0.58(0.30-1.02)$ & 10 & $0.37(0.18-0.68) \dagger$ \\
\hline Violence (27) & 17 & $0.48(0.28-0.77) \dagger$ & 9 & $0.61(0.28-1.15)$ & 8 & $0.39(0.17-0.76) \dagger$ \\
\hline Other causes (residual and blank codes; 28 ) & 32 & $0.64(0.44-0.90) \dagger$ & 6 & $0.41(0.15-0.90) \ddagger$ & 26 & $0.73(0.48-1.07)$ \\
\hline \multicolumn{7}{|c|}{$\begin{array}{l}\text { Data are number or standardised mortality ratios }(95 \% \mathrm{Cl}) \text {. Causes of death are from the National Institute for Occupational Safety and Health (NIOSH) major cause of death } \\
\text { categories and are listed with the associated NIOSH number in parentheses. The New York City population was used as the reference population. International Classification of } \\
\text { Diseases, } 10 \text { th revision, codes for NIOSH categories have been published elsewhere. }{ }^{21} \mathrm{SMR}=\text { standardised mortality ratio. MN=malignant neoplasm. }{ }^{*} \text { Non-rescue and } \\
\text { non-recovery worker category includes residents, workers, school students and staff, and passers-by of the lower Manhattan area on Sept } 11,2001 \text {. } t p<0 \cdot 01 \text {. } \neq p<0.05 \text {. }\end{array}$} \\
\hline
\end{tabular}

Cox proportional hazards regression models were used to estimate hazard ratios and $95 \%$ CIs for mortality in people of all ages. Separate models were constructed for rescue and recovery participants and non-rescue and non-recovery participants. To assess whether selfreferral to the Registry biased the relation between the level of WTC-related exposure and overall mortality, we further stratified our analysis of the association between exposure and mortality in non-rescue and non-recovery participants by study recruitment source. Individuals with missing exposure data were excluded from multivariable models. Multivariable hazard ratios were adjusted for covariates associated with mortality which had a p value less than $0 \cdot 20$ in bivariable analyses: age, sex, race and ethnic origin, income, smoking, and, for non-rescue and non-recovery participants, Registry recruitment source (self-identified vs list-identified). We also included history of chronic disease before $9 / 11$ in models of all-cause mortality, and history of heart disease or diabetes in models of heart-disease-related mortality. Rescue and recovery workers who worked exclusively on Staten Island, barges, or transfer stations were excluded because the exposure information obtained in the wave-one survey was insufficiently detailed to allow categorisation.

We assessed the trends in the hazard ratios for exposures by including each exposure as a continuous variable in a multivariable model and testing whether its coefficient was significantly different from zero. There was no evidence that the data violated the proportional hazards assumption. Analyses of proportional hazards were done with SAS version 9.2. 


\begin{tabular}{|c|c|c|c|c|c|c|}
\hline & \multicolumn{2}{|c|}{ All participants } & \multicolumn{2}{|c|}{$\begin{array}{l}\text { Rescue and recovery } \\
\text { participants }\end{array}$} & \multicolumn{2}{|c|}{$\begin{array}{l}\text { Non-rescue and non-recovery } \\
\text { participants* }\end{array}$} \\
\hline & $n$ & $\operatorname{SMR}(95 \% \mathrm{Cl})$ & $\mathrm{n}$ & $\operatorname{SMR}(95 \% \mathrm{Cl})$ & $\mathrm{n}$ & $\operatorname{SMR}(95 \% \mathrm{Cl})$ \\
\hline \multicolumn{7}{|l|}{ Haematological malignancies } \\
\hline Hodgkin's disease (037) & 1 & $0.94(0.02-5.24)$ & 1 & $2.62(0.07-14.59)$ & 0 & $0.00(0.00-5.42)$ \\
\hline Non-Hodgkin's lymphoma (038) & 13 & $0.96(0.51-1.65)$ & 1 & $0.26(0.01-1.46)$ & 12 & $1.24(0.64-2.17)$ \\
\hline Multiple myeloma (039) & 4 & $0.58(0.16-1 \cdot 48)$ & 1 & $0.59(0.01-3 \cdot 29)$ & 3 & $0.57(0.12-1 \cdot 68)$ \\
\hline Leukaemia (040) & 9 & $0 \cdot 76(0 \cdot 35-1 \cdot 44)$ & 2 & $0.65(0.08-2 \cdot 34)$ & 7 & $0.80(0.32-1.64)$ \\
\hline \multicolumn{7}{|c|}{ Mental psychoneurotic and personality disorders } \\
\hline Alcoholism (049) & 6 & $0.47(0.17-1.03)$ & 1 & $0.18(0.00-1.00) \dagger$ & 5 & $0.70(0.23-1.63)$ \\
\hline Other mental disorders $(050) \ddagger$ & 16 & $1 \cdot 23(0 \cdot 70-1 \cdot 99)$ & 8 & $2 \cdot 18(0 \cdot 94-4 \cdot 29)$ & 8 & $0.85(0.37-1 \cdot 68)$ \\
\hline \multicolumn{7}{|l|}{ Violence } \\
\hline Intentional self-harm (116) & 10 & $0.57(0.27-1.04)$ & 6 & $0 \cdot 81(0 \cdot 30-1 \cdot 77)$ & 4 & $0.39(0.11-1 \cdot 00)$ \\
\hline Assault and homicide (117) & 7 & $0.42 \dagger(0.17-0.87)$ & 3 & $0.43(0.09-1 \cdot 26)$ & 4 & $0.41(0.11-1.06)$ \\
\hline \multicolumn{7}{|c|}{$\begin{array}{l}\text { Data are number or standardised mortality ratios }(95 \% \mathrm{Cl}) \text {. Causes of death are from the } 119 \text { National Institute for Occupational Safety and Health }(\mathrm{NIOSH}) \text { minor cause of } \\
\text { death categories and are listed with the associated NIOSH number in parentheses. The New York City population was used as the reference population. International } \\
\text { Classification of Diseases, } 10 \text { th revision, codes for NIOSH categories have been published elsewhere. }{ }^{21} \text { SMR=standardised mortality ratio. }{ }^{*} \text { The category of non-rescue and } \\
\text { non-recovery participants includes residents, workers, school students and staff, and passersby of the lower Manhattan area on } 9 / 11 \text {. } \dagger p<0 \cdot 05 \text {. } \neq \text { Specific causes of death } \\
\text { categorised as other mental disorders in rescue and recovery participants: use of opioids }(n=2) \text {; use of cocaine }(n=2) \text {; use of multiple drugs and other psychoactive substances } \\
(n=3) \text {, and abuse of non-dependence-producing substances }(n=1) \text {. Specific causes of death categorised as other mental disorders in non-rescue and non-recovery } \\
\text { participants: dementia }(n=3) \text {; use of opioids }(n=1) \text {; use of cocaine }(n=1) \text {; and abuse of non-dependence-producing substances }(n=3) \text {. }\end{array}$} \\
\hline
\end{tabular}

\section{Role of the funding source}

The CDC's Agency for Toxic Substances and Disease Registry (ATSDR) supported the collection of survey data used in our analysis and participated in the overall design of the Registry, including the initial mortality study design. The sponsors of the study had no role in mortality study data linkage activities, data analysis, data interpretation, or writing of the report. New York City Department of Health and Mental Hygiene supported mortality matching infrastructure development and had a role in the design, data collection, development, and review of the manuscript. The corresponding author had full access to all data and had final responsibility to submit for publication.

\section{Results}

Table 1 shows the characteristics of the study group. Median age at 9/11 was 39 (range 12-94) years for rescue and recovery participants and 41 (0-97) years for nonrescue and non-recovery participants. Most rescue and recovery participants were men, whereas over half nonrescue and non-recovery participants were women (table 1). A history of smoking was more common in rescue and recovery participants. About a quarter of those who did rescue and recovery work also had WTC-related exposures at their residences, offices, or schools.

Linkage to mortality data from New York City vital records identified 745 deaths occurring between study enrolment and Dec 31, 2009, and linkage to the National Death Index identified 45 additional deaths up to Dec 31, 2007, for a total of 790 deaths. ICD-10 codes for underlying cause of death were unavailable for two of the deceased. 156 deaths occured in rescue and recovery participants and 634 in non-rescue and non-recovery participants. Of the two decedents aged less than 15 years at death, one died at age 5 years of a brain neoplasm (ICD-10 C71.9), the other at age 14 of a congenital brain malformation (ICD-10 Q04.9). These deaths were not included in SMR calculations, but were included in proportional hazards models.

SMRs for all causes of death were significantly lower than expected for both rescue and recovery participants and non-rescue and non-recovery participants (table 2). No significant increases in SMRs occurred for the major cause of death categories, including respiratory-system diseases, heart diseases, and haematological malignancies; many causes occurred significantly less than expected. One death was due to thyroid cancer (SMR 0.72, 95\% CI 0.02-3.99). Other leading causes of cancer deaths in the USA were cancer of the breast (SMR 0.77, 95\% CI 0.51-1.13), colon $(0 \cdot 70,0 \cdot 44-1 \cdot 06)$, rectum $(0 \cdot 68,0 \cdot 19-1 \cdot 74)$, trachea, bronchus, and lung $(0 \cdot 77,0 \cdot 59-0.99)$, prostate $(0 \cdot 59,0 \cdot 28-1 \cdot 08)$, and pancreas $(1 \cdot 03,0 \cdot 66-1 \cdot 55)$.

Table 3 shows SMRs for selected causes of death of a priori interest, grouped according to the NIOSH cause of death categories. None of the SMRs were significantly increased, including those for multiple myeloma and other haematological malignancies, alcoholism, mental disorders, and suicide.

In the 119 NIOSH cause-of-death categories, the only significantly increased SMR was for benign neoplasms of the eye, brain, or other nervous system among all participants (SMR 6.48, 95\% CI 1.34-18.94, n=3). 
These deaths were due to meningioma, and occurred in 2005 (in non-rescue and non-recovery participants aged 47 and 67 years) and 2008 (a rescue and recovery worker aged 64 years).

We examined relations between mortality and WTCrelated exposure levels within the cohort, with low levels of exposures used as the reference categories. Table 4 shows adjusted hazard ratios for all-cause mortality. The level of WTC-related exposure was not significantly associated with all-cause mortality in rescue and recovery participants ( $\mathrm{p}$ for trend $0 \cdot 49$ ). In non-rescue and non-recovery participants, both intermediate and high levels of exposure were associated with mortality compared with low exposure ( $\mathrm{p}$ for trend 0.003 ; table 4 ). In a subanalysis of non-rescue and non-recovery participants stratified by study recruitment source, the magnitude of the association between WTC exposure and mortality was similar in self-identified and listidentified participants (table 5).

In non-rescue and non-recovery participants, a high level of exposure was significantly associated with heartdisease-related death (table 6). Small participant numbers

\begin{tabular}{|c|c|c|c|c|c|c|}
\hline & \multicolumn{3}{|c|}{ Rescue and recovery participants* } & \multicolumn{3}{|c|}{ Non-rescue and non-recovery participants $\dagger$} \\
\hline & $\begin{array}{l}\text { Person-years of } \\
\text { observation }\end{array}$ & $\begin{array}{l}\text { Number of } \\
\text { deaths } \neq\end{array}$ & $\begin{array}{l}\text { Adjusted hazard } \\
\text { ratio }(95 \% \mathrm{Cl})\end{array}$ & $\begin{array}{l}\text { Person-years of } \\
\text { observation }\end{array}$ & $\begin{array}{l}\text { Number of } \\
\text { deaths } \neq\end{array}$ & $\begin{array}{l}\text { Adjusted hazard } \\
\text { ratio }(95 \% \mathrm{Cl})\end{array}$ \\
\hline Age on $9 / 11$ (years) &.. &.. & $1.07(1.05-1.09)$ & .. &.. & $1.09(1.08-1.10)$ \\
\hline \multicolumn{7}{|l|}{ Sex } \\
\hline Male & 56365 & 131 & $2 \cdot 25(1 \cdot 38-3 \cdot 68)$ & 65742 & 287 & $1.40(1.19-1 \cdot 65)$ \\
\hline Female & 17562 & 19 & Reference & 93531 & 331 & Reference \\
\hline \multicolumn{7}{|l|}{ Race and ethnic origin } \\
\hline White & 42308 & 76 & Reference & 81022 & 307 & Reference \\
\hline Black & 10782 & 35 & $1.72(1.14-2 \cdot 61)$ & 26597 & 101 & $1.27(1.01-1 \cdot 61)$ \\
\hline Hispanic & 15252 & 28 & $1 \cdot 11(0 \cdot 70-1 \cdot 74)$ & 24055 & 69 & $0.93(0.71-1.23)$ \\
\hline Other or missing & 5585 & 11 & $1.10(0.57-2.15)$ & 27598 & 141 & $0.91(0.72-1.13)$ \\
\hline \multicolumn{7}{|c|}{ Study recruitment source } \\
\hline Self-identified &.. & .. &.$\cdot$ & 122394 & 426 & Reference \\
\hline List-identified &.$\cdot$ &.$\cdot$ &.. & 36879 & 192 & $0.99(0 \cdot 82-1 \cdot 17)$ \\
\hline \multicolumn{7}{|c|}{ Total household income (\$US) in 2002} \\
\hline$<25000$ & 7260 & 20 & $1.67(0.96-2.89)$ & 26884 & 236 & $1.52(1.16-1.99)$ \\
\hline $25000-49999$ & 19498 & 44 & $1 \cdot 34(0.87-2 \cdot 07)$ & 49430 & 197 & $1 \cdot 37(1.06-1 \cdot 76)$ \\
\hline $50000-74999$ & 19805 & 41 & $1.29(0.84-1 \cdot 97)$ & 27346 & 74 & $1.23(0.91-1.66)$ \\
\hline$\geq 75000$ & 27170 & 45 & Reference & 51085 & 104 & Reference \\
\hline \multicolumn{7}{|c|}{ Smoking status at study enrolment } \\
\hline Never & 39171 & 56 & Reference & 96673 & 284 & Reference \\
\hline Former & 19115 & 47 & $1.24(0.83-1.85)$ & 37383 & 207 & $1.15(0.96-1 \cdot 39)$ \\
\hline Current & 14912 & 45 & $2.07(1.40-3.08)$ & 23398 & 113 & $2 \cdot 16(1 \cdot 72-2 \cdot 70)$ \\
\hline \multicolumn{7}{|c|}{ History of chronic illness before $9 / 115$} \\
\hline Yes & 6250 & 29 & $1.65(1.08-2.51)$ & 18370 & 255 & $1.90(1 \cdot 60-2 \cdot 26)$ \\
\hline No & 66182 & 116 & Reference & 137946 & 341 & Reference \\
\hline \multicolumn{7}{|c|}{ WTC-related rescue and recovery exposure level $\mathbf{\Upsilon}$} \\
\hline Low & 5147 & 9 & Reference &.$\cdot$ &.. &.. \\
\hline Intermediate & 59636 & 121 & $1.03(0.52-2 \cdot 06)$ &.. &.. & .. \\
\hline High & 9144 & 20 & $1.25(0.56-2 \cdot 78)$ & .. & .. & .. \\
\hline \multicolumn{7}{|c|}{ WTC-related residential, office, school, or transit exposure level $\boldsymbol{\Phi}$} \\
\hline Low &.$\cdot$ & .. &.$\cdot$ & 74497 & 173 & Reference \\
\hline Intermediate & .. & .. & .. & 72923 & 390 & $1.22(1.01-1 \cdot 48)$ \\
\hline High &.. & .. &.$\cdot$ & 11853 & 55 & $1 \cdot 56(1.15-2 \cdot 12)$ \\
\hline \multicolumn{7}{|c|}{ 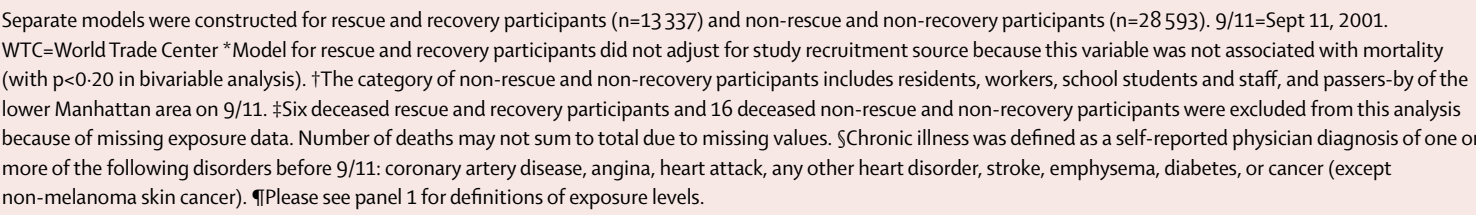 } \\
\hline
\end{tabular}




\begin{tabular}{|c|c|c|c|c|c|c|}
\hline & \multicolumn{3}{|c|}{ Self-identified participants } & \multicolumn{3}{|c|}{ List-identified participants } \\
\hline & $\begin{array}{l}\text { Person-years of } \\
\text { observation }\end{array}$ & $\begin{array}{l}\text { Number of } \\
\text { deaths } †\end{array}$ & $\begin{array}{l}\text { Adjusted hazard ratio } \\
(95 \% \mathrm{Cl})\end{array}$ & $\begin{array}{l}\text { Person-years of } \\
\text { observation }\end{array}$ & $\begin{array}{l}\text { Number of } \\
\text { deaths } †\end{array}$ & $\begin{array}{l}\text { Adjusted hazard ratio } \\
(95 \% \mathrm{Cl})\end{array}$ \\
\hline Low & 55177 & 116 & Reference & 19320 & 57 & Reference \\
\hline Intermediate & 57554 & 270 & $1.30(1.04-1.64)$ & 15369 & 120 & $1.07(0.76-1.51)$ \\
\hline High & 9663 & 40 & $1.63(1.13-2 \cdot 34)$ & 2190 & 15 & $1.46(0.82-2.61)$ \\
\hline \multicolumn{7}{|c|}{$\begin{array}{l}\text { Lists of potentially eligible people were obtained from lower Manhattan area employers and government agencies (list-identified participants), and broad-based, } \\
\text { multilingual media campaigns encouraged World Trade Center (WTC) exposed people to contact the WTC Health Registry via a website or toll-free telephone number for } \\
\text { eligibility screening (self-identified participants). Model for non-rescue and non-recovery participants ( } \mathrm{n}=28593 \text { ) adjusted for sex, age, race and ethnic origin, income, } \\
\text { smoking status, and history of chronic illness before Sept } 11,2001 \text {. *Please see panel } 1 \text { for definitions of exposure levels. } \dagger 16 \text { deceased non-rescue and non-recovery } \\
\text { participants were excluded from this analysis because of missing exposure data. }\end{array}$} \\
\hline
\end{tabular}

\begin{tabular}{|c|c|c|c|}
\hline & $\begin{array}{l}\text { Person-years of } \\
\text { observation }\end{array}$ & $\begin{array}{l}\text { Number of } \\
\text { heart-disease } \\
\text { deaths } \ddagger\end{array}$ & $\begin{array}{l}\text { Adjusted hazard } \\
\text { ratio }(95 \% \mathrm{Cl})\end{array}$ \\
\hline Low & 74497 & 34 & Reference \\
\hline Intermediate & 72923 & 99 & $1.21(0.80-1.83)$ \\
\hline High & 11853 & 14 & $2.06(1.10-3 \cdot 86)$ \\
\hline \multicolumn{4}{|c|}{$\begin{array}{l}\text { Model for non-rescue and non-recovery participants ( } \mathrm{n}=28593 \text { ) adjusted for sex, } \\
\text { age, income, smoking status, pre- } 9 / 11 \text { diabetes, pre- } 9 / 11 \text { heart disease, and study } \\
\text { recruitment source (self-identified vs list-identified). Non-rescue and non-recovery } \\
\text { participant category includes residents, workers, and school students and staff, } \\
\text { and passers-by of lower Manhattan area on } 9 / 11 \text {. } † \text { See panel } 1 \text { for definitions of } \\
\text { exposure levels. ¥Six rescue and recovery participants who died due to heart } \\
\text { disease were excluded from this analysis because of missing exposure data. }\end{array}$} \\
\hline \multicolumn{4}{|c|}{$\begin{array}{l}\text { Table 6: Adjusted hazard ratios for heart-disease-related mortality } \\
\text { among non-rescue and non-recovery participants, by WTC-related } \\
\text { residential, office, school, or transit exposure level }{ }^{\star} \dagger\end{array}$} \\
\hline
\end{tabular}

prevented further exploration of other specific causes of death, including deaths related to heart disease in rescue and recovery participants.

In models including both rescue and recovery and nonrescue and non-recovery participants and adjusted for the covariates shown in table 4 and table 5 , dust cloud exposure on $9 / 11$ was not associated with all-cause mortality (adjusted hazard ratio $0 \cdot 97,95 \%$ CI $0 \cdot 84-1 \cdot 12$ ) or with mortality related to heart disease $(1 \cdot 04,0 \cdot 77-1 \cdot 42)$.

\section{Discussion}

We did not identify excess overall mortality in the WTC Health Registry cohort between 2003 and 2009 relative to New York City rates. Within the cohort, however, high levels of WTC-related exposure were associated with an increased risk of all-cause mortality and heart-diseaserelated mortality in non-rescue and non-recovery participants, with hazard ratios that suggested a doseresponse relation (panel 2).

Because most illnesses that are established or possible sequelae of WTC-related exposures have long latency or long median survival periods, the absence of a relation between reported dust-cloud exposure by itself and mortality risk in our study is not surprising. For nonrescue and non-recovery participants, a high level of exposure meant having two or more injuries on $9 / 11$, not evacuating their home on $9 / 11$ (for area residents), and being present at school on 9/11 (for area students and school staff). This combination of WTC exposures identifies a subgroup whose overall exposure level was more intense than that of other non-rescue and nonrecovery participants. Our data are not sufficiently precise to identify specific exposures responsible for increased mortality risk. Therefore, our findings do not single out this highly exposed subgroup alone for clinical surveillance. They do, however, support long-term monitoring of the health of all $9 / 11$ survivors, with emphasis on modification of risk factors for heart disease.

Although a long observation period might be necessary to detect excess deaths due to most chronic illnesses, our findings suggest that, by the end of 2009, the number of deaths in this study population was lower than what would be expected in the New York City general population. A deficit in mortality has been reported during the early years of observation in many other (nonWTC) cohort studies of volunteers, and of young people. ${ }^{22-25}$ This deficit might be due in part to the healthy worker effect-an occurrence of lower-than-expected mortality in worker cohorts that is generally attributed to the high baseline level of health required to enter and remain in the workforce. ${ }^{26} \mathrm{An}$ analogous effect has been seen in people who volunteer for health studies, and also might have contributed to the low relative mortality in both rescue and recovery and non-rescue and nonrecovery participants..$^{24}$

The only significantly raised SMR was for meningiomarelated deaths. Meningiomas related to radiation exposure, the single known aetiological risk factor for this form of cancer, usually have a latency period of 20 years or more, ${ }^{27}$ so our finding was most probably due to chance. We also identified a two-times increase in substance-related deaths for rescue and recovery participants (table 3).

Because objective measures of WTC-related exposure are not available, our study relied on self-reported exposure data. We developed summary categories of WTC-related exposure that were sufficiently distinct from 
Panel 2: Research in context

\section{Systematic review}

This is the first comprehensive report on mortality in survivors of the Sept 11, 2001 World Trade Center Disaster. We searched PubMed for reports published from Sept 11, 2001, to Feb 28, 2011, using the search terms "September 11 Terrorist Attacks", "World Trade Center", "WTC", and "September 11, 2001" without language restrictions. To ensure comprehensiveness, we compared the results of our search with relevant literature reviews. No population-based studies on mortality had been published at the time of the search.

\section{Interpretation}

Among World Trade Center Health Registry participants residing in New York City, overall death rates in 2003-09 were not higher than expected when compared to the general New York City population. However, within the cohort, non-rescue and non-recovery participants with high levels of WTC-related exposure had an increased risk of all-cause mortality and heart-disease-related mortality compared with those with low exposure. Continued monitoring of all-cause mortality and disease-specific mortality will be needed.

one another to enable comparisons within each of the two subcohorts. These categories were based on individual exposure variables, which have consistently been associated with asthma, PTSD, and other health outcomes in previous analyses. ${ }^{1,28}$

In keeping with a previous finding that injury during the disaster was associated with post-9/11 PTSD, ${ }^{29}$ injuries sustained by Registry participants on $9 / 11$ were a key component of the WTC-exposure definition for nonrescue and non-recovery participants. The type of injury most frequently reported by participants was eye injury or irritation, which might have been less severe than other injuries queried (such as a broken or dislocated bone), and thus a less powerful indicator of high overall exposure. Therefore, to ensure that our definition captured the most exposed group, two or more injuries were required for the highest exposure level in nonrescue and non-recovery workers. Additional exploration of the relation between acute injuries sustained by individuals on $9 / 11$ and overall mortality is needed.

To assess whether self-selection bias could have influenced our findings, we assessed whether study recruitment source (list-identification vs self-identification) was an important confounding variable for the relation between WTC exposure and mortality. In bivariable analysis, study recruitment source was significantly associated with mortality in non-rescue and non-recovery participants, whereas it was not significant in rescue and recovery participants. We therefore included this variable in the multivariable model for non-rescue and nonrecovery participants. We also stratified our analysis of the relation between WTC-related exposures and overall mortality in non-rescue and non-recovery participants by study recruitment source. The association between WTC exposure and mortality was not significant in listidentified participants, probably because of the small size of this subgroup. However, the magnitude of the association was similar in the two groups, suggesting that the exposure-outcome relation did not differ substantially according to study recruitment source.

During the months of disruption and concerted rescue and recovery efforts after the $9 / 11$ disaster, most people directly exposed to the events of $9 / 11$ in New York City were not enumerated. Since systematic sampling of the exposed population was not possible, we recruited potentially eligible people into the Registry from several groups who were known to be directly affected, including rescue and recovery workers and lower Manhattan area residents and workers. A previous Registry study using raking ratio estimation and census demographics suggested that WTC-exposure-outcome relations in residents of the lower Manhattan area were probably representative of such relations in the larger affected population. ${ }^{28}$ Characteristics of Registry rescue and recovery participants were similar to those of rescue and recovery workers assessed in the WTC worker and volunteer medical screening programme. ${ }^{20}$ An exception, a difference in the proportion of workers arriving on $9 / 11$ $(40.5 \%$ of rescue and recovery workers in the medical screening programme compared with $25.5 \%$ of those in the Registry), probably exists because the screening programme's goal was to identify WTC-related physical or mental health problems, whereas the Registry aimed to recruit all WTC-exposed people.

We also compared Registry participants who reported being firefighters employed by the Fire Department of New York City (FDNY) with a published description of 10870 FDNY firefighters who were present at the WTC disaster. ${ }^{2}$ We identified similarity between demographic and exposure characteristics of the two samples (data not shown). Beyond these comparisons, however, full definition of the representativeness of our sample is not possible, which might limit the generalisability of our study results.

We did not have sufficient statistical power for detailed analyses of the relations between WTC-related exposures and most specific causes of death, because of the short observation period. Our SMR calculations did not include the two participants aged 14 years or younger, one of whom died of a brain neoplasm and the other of a congenital brain malformation. Although our results mirror certain well-established risk factors for premature mortality in New York and the USA overall, including smoking status and black versus white race, ${ }^{30,31}$ we did not have data for other known risk factors of mortality, including body-mass index and alcohol use. We plan to gather such data in future questionnaires.

Despite these limitations, this exploratory study comprehensively depicts mortality in a well-defined 
cohort of $9 / 11$ survivors, providing a baseline for continued surveillance. Results suggest that screening for and management of modifiable risk factors associated with heart disease, including smoking, might be of particular importance in this population. It will be crucial to determine whether these associations are sustained with extended observation, and whether such associations become apparent in rescue and recovery participants.

\section{Contributors}

RMB, MRF, and JEC initiated the study. JEC, JK, and HTJ undertook and supervised the collection of mortality data. HTJ, JEC, JL, and ID prepared data for analysis. HTJ drafted the report and did the main statistical analysis with input from SDS, JEC, LS, JL, CMG, JLH, RMB, and ID. All authors participated in interpretation of the final results and editing of the report. All authors saw and approved the final version of the report.

\section{Conflicts of interest}

We declare that we have no conflicts of interest.

\section{Acknowledgments}

This study was supported by Cooperative Agreement U50/ATU272750 from the Agency for Toxic Substances and Disease Registry (ATSDR) of the US Centers for Disease Control and Prevention (CDC), which included support from the National Center for Environmental Health (NCEH); Cooperative Agreement $1 \mathrm{U} 50 / \mathrm{OH} 009739$ from the National Institute for Occupational Safety and Health (NIOSH); and the New York City Department of Health and Mental Hygiene (NYC DOHMH). We thank the World Trade Center Health Registry participants; Gracie Han for her role in establishing the methods for gathering mortality data; Mary Schubauer-Berigan and James Yiin for their assistance with the LTAS statistical software; and Robert Bilgrad for his assistance with obtaining and interpreting National Death Index results. The views expressed in this article are those of the authors and do not necessarily represent the views of ATSDR, NIOSH, NCEH, or NYC DOHMH.

\section{References}

1 Brackbill RM, Hadler JL, DiGrande L, et al. Asthma and posttraumatic stress symptoms 5 to 6 years following exposure to the World Trade Center terrorist attack. JAMA 2009; 302: 502-16.

2 Aldrich TK, Gustave J, Hall CB, et al. Lung function in rescue workers at the World Trade Center after 7 years. N Engl J Med 2010; 362: 1263-72.

3 Weiden MD, Ferrier N, Nolan A, et al. Obstructive airways disease with air trapping among firefighters exposed to World Trade Center dust. Chest 2010; 137: 566-74.

4 Reibman J, Lin S, Hwang SA, et al. The World Trade Center residents' respiratory health study: new-onset respiratory symptoms and pulmonary function. Environ Health Perspect 2005; 113: 406-11.

5 Berninger A, Webber MP, Cohen HW, et al. Trends of elevated PTSD risk in firefighters exposed to the World Trade Center disaster: 2001-2005. Public Health Rep 2010; 125: 556-66.

6 Stellman JM, Smith RP, Katz CL, et al. Enduring mental health morbidity and social function impairment in World Trade Center rescue, recovery, and cleanup workers: the psychological dimension of an environmental health disaster. Environ Health Perspect 2008; 116: $1248-53$.

7 Lioy PJ, Weisel CP, Millette JR, et al. Characterization of the dust/ smoke aerosol that settled east of the World Trade Center (WTC) in lower Manhattan after the collapse of the WTC 11 September 2001. Environ Health Perspect 2002; 110: 703-14.

8 Pleil JD, Vette AF, Johnson BA, Rappaport SM. Air levels of carcinogenic polycyclic aromatic hydrocarbons after the World Trade Center disaster. Proc Natl Acad Sci USA 2004; 101: 11685-88.

9 Landrigan PJ, Lioy PJ, Thurston G, et al. Health and environmental consequences of the World Trade Center disaster.

Environ Health Perspect 2004; 112: 731-39.
10 Moline JM, Herbert R, Crowley L, et al. Multiple myeloma in World Trade Center responders: a case series. J Occup Environ Med 2009; 51: 896-902.

11 Gullette ECD, Blumenthal JA, Babyak M, et al. Effects of mental stress on myocardial ischemia during daily life. JAMA 1997; 277: $1521-26$

12 Dominici F, Peng RD, Bell ML, et al. Fine particulate air pollution and hospital admission for cardiovascular and respiratory diseases. JAMA 2006; 295: 1127-34.

13 Lin S, Gomez MI, Gensburg L, Liu W, Hwang SA. Respiratory and cardiovascular hospitalizations after the World Trade Center disaster. Arch Environ Occup Health 2010; 65: 12-20.

14 Allegra J, Mostashari F, Rothman J, Milano P, Cochrane D. Cardiac events in New Jersey after the September 11, 2001, terrorist attack. J Urban Health 2005; 82: 358-63.

15 Farfel M, DiGrande L, Brackbill R. An overview of 9/11 experiences and respiratory and mental health conditions among World Trade Center Health Registry enrollees. J Urban Health 2008; 85: 880-909.

16 WHO. International Statistical Classification of Diseases and Related Health Problems. Tenth Revision. Geneva: World Health Organization, 1992. http://www.who.int/classifications/icd/en/ (accessed Feb 23, 2011)

17 Schubauer-Berigan M, Hein MJ, Raudabaugh WM, et al. Update of the NIOSH Life Table Analysis System: a person-years analysis program for the Windows computing environment. Am I Ind Med (in press).

18 Wheeler K, McKelvey W, Thorpe L, et al. Asthma diagnosed after 11 September 2001 among rescue and recovery workers: findings from the World Trade Center Health Registry. Environ Health Perspect 2007; 115: 1584-90.

19 Banauch GI, Alleyne D, Sanchez R, et al. Persistent hyperreactivity and reactive airway dysfunction in firefighters at the World Trade Center. Am J Respir Crit Care Med 2003; 168: 54-62.

20 Herbert R, Moline J, Skloot G, et al. The World Trade Center disaster and the health of workers: five-year assessment of a unique medical screening program. Environ Health Perspect 2006; 114: 1853-58.

21 Robinson CF, Schnorr TM, Cassinelli RT, et al. Tenth revision US mortality rates for use with the NIOSH Life Table Analysis System. J Occup Environ Med 2006; 48: 662-67.

$22 \mathrm{Li} \mathrm{CY}$, Sung FC. A review of the healthy worker effect in occupational epidemiology. Occup Med (Lond) 1999; 49: 225-29.

23 Burnell M, Gentry-Maharaj A, Ryan A, et al. Impact on mortality and cancer incidence rates of using random invitation from population registers for recruitment to trials. Trials 2011; 12: 61.

24 Lindsted KD, Fraser GE, Steinkohl M, Beeson WL. Healthy volunteer effect in a cohort study: temporal resolution in the Adventist health study. J Clin Epidemiol 1996; 49: 783-90.

25 Pinsky PF, Miller A, Kramer BS, et al. Evidence of a healthy volunteer effect in the Prostate, Lung, Colorectal, and Ovarian Cancer Screening Trial. Am J Epidemiol 2007; 165: 874-881.

26 Checkoway H, Eisen EA. Developments in occupational cohort studies. Epidemiol Rev 1998; 20: 100-11.

27 Sadetzki S, Modan B, Chetrit A, Freedman L. An iatrogenic epidemic of benign meningioma. Am I Epidemiol 2000; 151: 266-72.

28 DiGrande L, Perrin MA, Thorpe LA, et al. Posttraumatic stress symptoms, PTSD, and risk factors among lower Manhattan residents 2-3 years after the September 11, 2001 terrorist attacks. J Trauma Stress 2008; 21: 264-73.

29 Galea S, Vlahov D, Resnick H, et al. Trends of probable post-traumatic stress disorder in New York City after the September 11 Terrorist Attacks. Am J Epidemiol 2003; 158: 514-24.

30 Fang J, Madhavan S, Alderman MH. The association between birthplace and mortality from cardiovascular causes among black and white residents of New York City. N Engl J Med 1996; 335: 1545-51.

31 Karpati A, Kerker B, Mostashari F, et al. Health disparities in New York City. New York: New York City Department of Health and Mental Hygiene, 2004. http://www.nyc.gov/html/doh/downloads/ pdf/epi/disparities-2004.pdf (accessed May 16, 2011). 